\section{REVIEW ARTICLE}

\title{
Replicative ageing and senescence in Saccharomyces cerevisiae and the impact on brewing fermentations
}

\author{
Christopher D. Powell, ${ }^{1}$ Sylvie M. Van Zandycke, ${ }^{1}$ David E. Quain ${ }^{2}$ \\ and Katherine A. Smart ${ }^{1}$
}

Author for correspondence: Katherine A. Smart. Tel: +44 1865 483248. Fax: +44 1865483242. e-mail: kasmart@brookes.ac.uk

${ }^{1}$ School of Biological and Molecular Sciences, Oxford Brookes University, Headington, Oxford OX3 OBP, UK

${ }^{2}$ Bass Brewers, Technical Centre, PO Box 12, Cross Street, Burton-on-Trent DE14 1XH, UK

Keywords: ageing, lifespan, yeast, senescence, brewing

\section{Overview}

Ageing is the predetermined progressive transition of an individual cell from youth to old age that finally culminates in death. Yeast replicative ageing is a function of the number of divisions undertaken by an individual cell, and may be measured by enumerating the number of bud scars on the cell surface. An aged yeast cell exhibits a distinct morphology and physiology from that of younger cells: the impact of such modifications in cellular function on fermentation performance is examined here. Although the precise mechanism of ageing has not been fully elucidated, the current theories are reviewed and discussed.

\section{Background}

As a consequence of yeast strain management and fermentation in the brewery, cell death may occur via one of two distinct pathways: necrosis and senescence. Necrosis may be defined as the accumulation of irreparable damage to intracellular components compromising cell integrity, leading to death and autolysis. Such damage occurs primarily as a result of exposure to excess stress or repeated exposure to low-level stress (Monch et al., 1995). Necrosis may also occur following the deletion or disruption of specific essential genes due to a mutagenic event (Oliver, 1996) or as a result of the accumulation of irreparable DNA damage (Lydall \& Weinert, 1996). In contrast, senescence is the predetermined cessation of life as a result of the genetically controlled progression from youth to old age.

That brewing yeast should lose viability due to necrosis is expected; however, it has not been recognized that in the absence of lethal doses of stress or DNA damage brewing yeast will progress through a structured and defined lifespan, eventually reaching a senescent phase which culminates in cell death. Primarily this is due to the fact that the term 'ageing' has been incorrectly used to describe any population of cells exhibiting a deteriorated physiological state. In the brewing industry, yeast age is measured chronologically in terms of the number of times a yeast population is serially repitched (recycled for reuse in successive fermentations). In addition, yeast which has been stored (in the form of a highly concentrated cell suspension, termed a slurry), or maintained in extended stationary phase is often referred to by brewers as aged. Such populations exhibit impaired physiological states, although their phenotypic characteristics more closely resemble those associated with necrosis than senescence.

The metric of the brewing yeast lifespan is not chronological but relates to the number of divisions an individual cell has undertaken (Hayflick \& Moorhead, 1961; Muller et al., 1980). The number of daughters produced by a mother cell, termed the divisional age, indicates the relative age of the cell, while the maximum lifespan potential of a cell is referred to as the Hayflick limit (Hayflick, 1965). Yeast longevity is determined by genes and influenced by environmental factors; however cells of the same genotype exhibit intrinsic variation in lifespan. Each yeast cell is capable of dividing a number of times before reaching senescence, in which no cell division occurs and death metabolism is initiated. This form of ageing is known as replicative senescence and is a phenomenon shared by both yeast and mammalian cells (Jazwinski, 1990a, 1993a, b; Austriaco, 1996; Campisi, 1996; Campisi et al., 1996; Kennedy \& Guarente 1996; Smith \& Pereira-Smith, 1996; Sinclair et al., 1998). Senescence is a consequence of termination of replication and is therefore intimately associated with cell division and hence the cell cycle. 


\section{The yeast cell cycle}

Yeast cultures, including those employed in brewery fermentations, are comprised of cells at varying stages of the cell cycle (George, 1996; Smart, 1999). The yeast cell cycle involves the progression through a series of events which enable the cell to complete a round of cellular vegetative reproduction known as division. Vegetative replication therefore incorporates all of the events associated with the preparation, production and release of daughter cells (Mitchison, 1971; Pringle \& Hartwell, 1981; Wheals, 1987; Walker, 1998). From the brewing perspective, progression through the cell cycle is critical for the formation of sufficient yeast biomass to support fermentation. In addition, a sufficient crop of yeast at the base ('cone') of the cylindroconical fermentation vessel is essential for subsequent harvesting and reuse (Stewart, 1996).

The cell cycle may be divided into five phases (Fig. 1): $\mathrm{G}_{0}, \mathrm{G}_{1}, \mathrm{~S}, \mathrm{G}_{2}$ and $\mathrm{M}$ (Pringle \& Hartwell, 1981; Wheals, 1987). DNA synthesis occurs during $S$ phase, while segregation of chromosomes during mitosis takes place at $M$ phase. $G_{1}$ and $G_{2}$ represent two 'gap' periods of variable length, during which organelle production and normal cell processes such as growth and development take place. Subsequent to M phase cell division occurs, although complete separation is not a prerequisite for continued reproduction (Wheals, 1987). Indeed, ineffective mother-daughter cell separation can result in chain formation, which is a characteristic phenotype of some brewing yeast strains.

During active growth, cell division rate is limited by the growth of an individual cell. The initiation of a new round of division is regulated by signalling pathways comprised of networks of gene-mediated events that monitor cell size (Pringle \& Hartwell, 1981), age (Jazwinski, 1990a), nutritional status (Pringle \& Hartwell, 1981), the presence of mating pheromone and the completion of the previous round of cell division
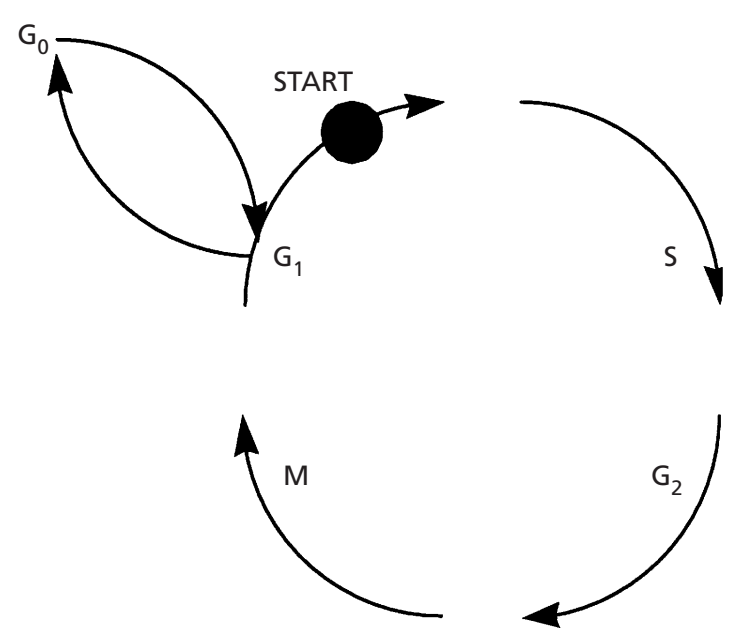

Fig. 1. The yeast cell cycle (adapted from Smart, 1999).
(Hartwell, 1974, 1978). These signalling pathways act together to form cell-cycle regulation points (Hartwell \& Weinhart, 1989), which confirm that the previous steps have been completed without errors (Forsburg \& Nurse, 1991; Bell \& Stillman, 1992; Diffley \& Cocker, 1992; Murray, 1994; Diffley, 1995).

$\mathrm{G}_{1}$ precedes the initiation of chromosomal DNA replication and represents the phase of growth in which cells must reach a minimum size before progressing through the remainder of the cell cycle (Futcher, 1996; Kuntzel et al., 1996; Breeden, 1996). Slow-growing cells have a relatively long generation time and this additional time is spent in the $G_{1}$ phase. In addition, daughter cells that have never produced a bud are smaller than their corresponding mother cells and so have longer $G_{1}$ phases. This differential is known as mother-daughter asymmetry, where mother and daughter cells may be distinguished by both cell size and division rate (Futcher, 1993; Lew \& Reed, 1995).

Towards the end of $G_{1}$ a ring of chitin appears on the cell surface, indicating the location of bud formation. Saccharomyces cerevisiae regulates its cycle at $G_{1}$ and particularly at a stage termed START (Hartwell et al., 1974; Wheals, 1987). After START has occurred, environmental factors such as external stress and poor nutrients are no longer able to prevent division. Thus even during the initial stages of fermentation when oxygen becomes limiting and cell division is no longer favoured, yeast cells that have passed through START are forced to complete the division to which they have been committed (Wheals, 1987). Budding is the obvious visible sign that a cell has initiated a round of division and in general, the larger the bud, the closer the cell is to completion of division (Wheals, 1987). During exponential growth the proportion of cells that have progressed through START and those that have not is roughly equal, and may be represented by the occurrence of $50 \%$ budded and $50 \%$ unbudded cells (Wheals, 1987; Futcher, 1993). Failure to progress through START results in cell-division arrest and entry into the cell cycle stationary phase, which is also known as $G_{0}$ (Forsburg, 1994).

$\mathrm{G}_{0}$ is an 'off cycle' state during which no net increase in cell number occurs (Wei et al., 1993; Werner-Washburne et al., 1993; Forsburg, 1994; Nurse, 1997). Entry into $G_{0}$ is triggered by adverse environmental factors, one of which is nutrient depletion (Werner-Washburne et al., 1993). During the latter stages of fermentation the yeast enters stationary phase and remains in this state during storage and repitching (McCaig \& Bendiak, 1985; D’Amore, 1992; Hammond 1993; Stewart 1996). A characteristic of organisms in $G_{0}$ phase is an increased resistance to stresses for an extended period of time (Pringle \& Hartwell, 1981; Wheals, 1987), causing cells to retain viability and vitality during cold storage (McCaig \& Bendiak, 1985).

Given the correct environmental conditions, yeast cells exit $G_{0}$ and re-enter the cell cycle to initiate a new round 
of cell division; therefore stationary phase is a reversible phenotype. Cells in extended stationary phase are often referred to as aged cultures, although in fact they are composed of individual cells exhibiting both young and aged phenotypes (Smart, 1999).

Providing the cell completes START and the remainder of the $G_{1}$ phase, it may then progress to the $S$ phase, where DNA is replicated and the nucleus migrates towards the neck separating mother from bud (Futcher, 1993; Wei et al., 1993; Weinert et al., 1994; O'Connell $\&$ Nurse, 1994). After another resting phase, $G_{2}$, the cell enters the $M$ phase where mitosis and nuclear division occurs (Nurse et al., 1998), and the bud emerges from within the chitin ring. Cytokinesis and cell separation are believed to occur in early $\mathrm{G}_{1}$ (reviewed by Pringle \& Hartwell, 1981; Forsburg \& Nurse, 1991; Nurse, 1997).

\section{Senescence and the cell cycle}

Senescence is reached when the final division of the cell has been achieved and permanent withdrawal into a $\mathrm{G}_{0}{ }^{-}$ like phase occurs so that further cell-cycle progression is impossible. Senescent cells arrest their growth with a $G_{1}$ DNA content and lose their ability to enter $S$ phase, probably due to the repression of some crucial growthregulatory genes (Campisi et al., 1996). However, such cells may remain viable and metabolically active for a long time. During the replications that precede this state, the cell is likely to acquire deleterious intracellular modifications that eventually result in the development of the ageing phenotype (Hayflick, 1965; Jazwinski, 1990b, 1993a, b; Campisi, 1996; Austriaco, 1996; Kenyon, 1996; Kennedy \& Guarente, 1996; Osiewacz, 1997; Sinclair et al., 1998).

\section{Life expectancy and yeast cells}

For S. cerevisiae the mean Hayflick limit may be as high as 30.9 divisions (Muller, 1971), although in most strains mean lifespan is generally found to occur within the range of 10-30 replications. The number of times a yeast cell is capable of dividing is thought to be species- and strain specific (Muller, 1971; Muller et al., 1980; Egilmez \& Jazwinski, 1989; Austriaco, 1996; Osiewacz, 1997; Sinclair et al., 1998), and individuals within a population demonstrate homology in their Hayflick limits (Mortimer \& Johnson, 1959; Barker \& Smart, 1996).

In contrast, a colony of yeast may be considered to be immortal because although individuals will senesce and die, the continual generation of new daughter cells ensures that the population is maintained indefinitely. Yeasts, like many other eukaryotes, reproduce using a replicative reset technique (Austriaco, 1996). Following mitosis, a mother and daughter cell are produced through an asymmetric division in which each cell can be readily distinguished (Fig. 2). The mother exhibits her personal Hayflick limit, whilst the daughter cell is 'reset' to zero and is capable of displaying a full replicative life span in accordance with the Hayflick

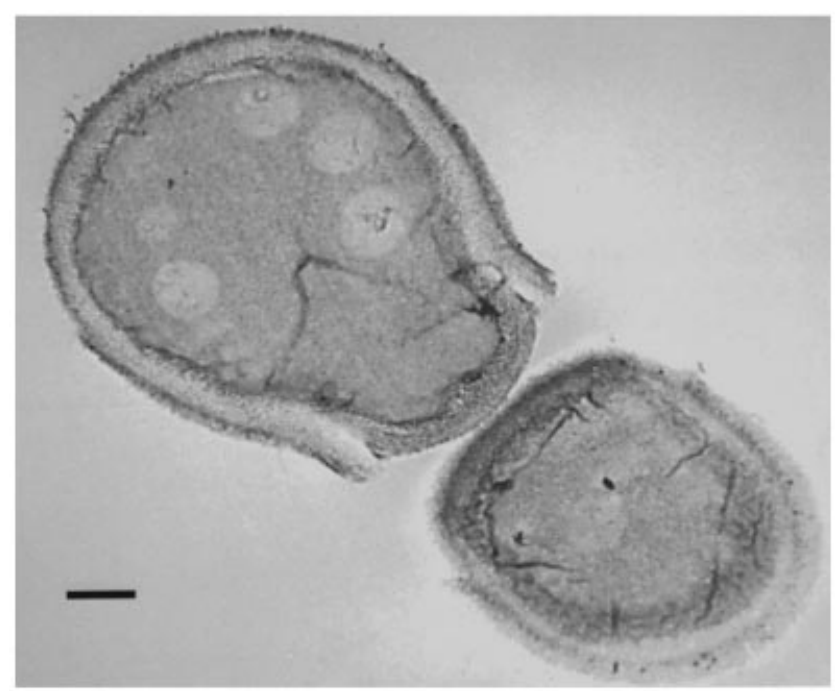

Fig. 2. Transmission electron micrograph of a lager yeast strain (KS1) mother cell which has just completed cytokinesis. The mother and daughter cells display asymmetry in terms of cell size. The mother cell's bud and daughter cell's birth scars are shown. Bar, $1 \mu \mathrm{m}$.

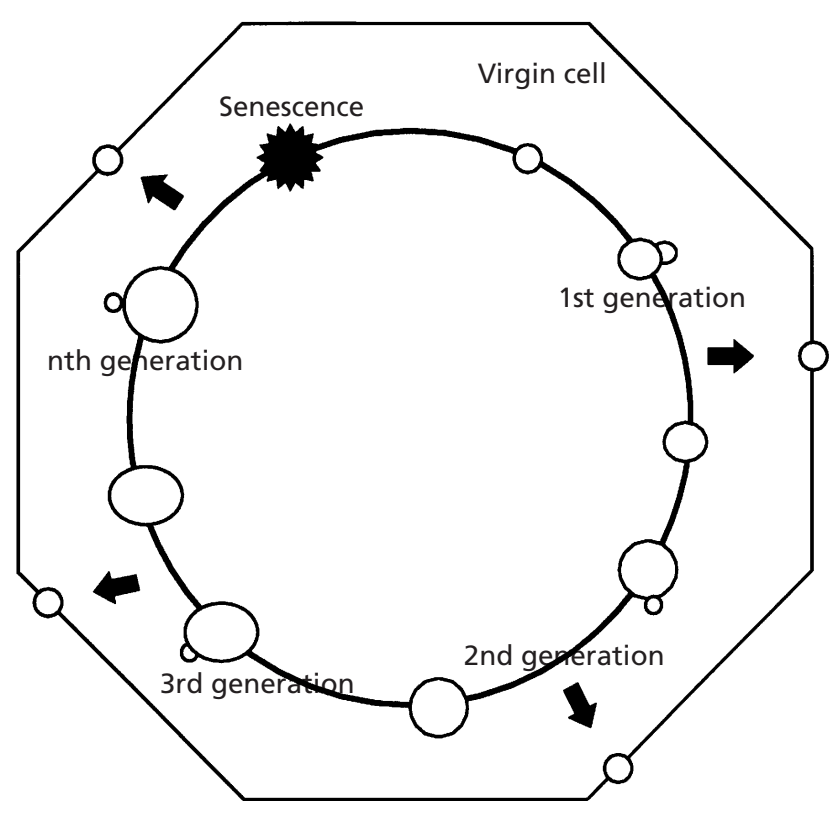

Fig. 3. The cell spiral model (adapted from Egilmez \& Jazwinski, 1989) which illustrates the progression from a newly emerged daughter cell (virgin cell) to senescence.

limit of its strain (Fig. 3). Continuous growth of a population is therefore possible under favourable environmental conditions.

Replicative reset ageing may however be defective (Mortimer \& Johnston, 1959; Kennedy et al., 1994), as demonstrated in some strains where the penultimate or ultimate division of an aged mother cell produces an 
imperfect daughter that is not capable of achieving the Hayflick limit characteristic for the strain (Kennedy et al., 1994; Barker \& Smart, 1996).

\section{Phenotypic characteristics associated with ageing and senescence}

The transition from youth to old age is characterized by a decrease in metabolic activity and several physiological changes (Jazwinski, 1990a, 1993b). Senescence is therefore typified by an arrest of cell division, deleterious cellular modifications and altered cell function. Some aspects of the latter are universally expressed by all cell types, others may be genus-, species- or even strain specific.

For yeast, ageing results in irreversible modifications to cellular appearance. The senescent phenotype gradually appears throughout the lifespan and the occurrence of certain modifications can often act as biomarkers in the determination of cell age. Several morphological and physiological changes associated with the ageing process in haploid, diploid and polyploid laboratory strains, and polyploid brewing production strains of yeast have been described. These include an increase in bud-scar number and therefore chitin deposition (Egilmez et al., 1990), an increase in cell size (Bartholomew \& Mittwer, 1953; Mortimer \& Johnston, 1959; Johnson \& Lu, 1975; Egilmez et al., 1990; Barker \& Smart, 1996), a granular appearance to aged cells (Mortimer \&
Johnston, 1959), accumulation of surface wrinkles (Mortimer \& Johnston, 1959; Muller, 1971; Barker \& Smart, 1996), and eventual cell lysis (Mortimer \& Johnston, 1959). Many other morphological and physiological changes have since been identified (Table 1).

Some ageing-associated morphological changes occur in order to counteract other potentially harmful aspects of lifespan progression. Wrinkling of the cell surface is likely to compensate for the decrease in surface area : volume ratio in larger and older cells (Mortimer \& Johnston, 1959; Muller, 1971; Jazwinski, 1993b). Aged yeast cells also accumulate refractile granules containing lipids reminiscent of the pigment lipofuscin, though as yet their function remains unknown (Katz et al., 1984). Gene expression is also known to vary considerably over the lifespan (Egilmez et al., 1989). This variation in expression has been shown to be both quantitative and qualitative in Drosophila (Fleming et al., 1988), enabling cells to produce proteins and enzymes which are of benefit at different stages of the lifespan.

\section{Mechanisms of ageing and senescence in S. cerevisiae}

The mechanism of ageing and senescence in S. cerevisiae is poorly understood. The earliest hypotheses concerning the mechanism of ageing in yeast involved the relationship between cell-division arrest and surface-tovolume ratio (Mortimer \& Johnston, 1959). As cells age

Table 1. Cellular changes accompanying senescence

\begin{tabular}{|c|c|c|}
\hline Characteristic & Change & Reference \\
\hline Cell size & Increase & Bartholomew \& Mittwer (1953), Johnson \& Lu (1975) \\
\hline Cell shape & Altered & Mortimer \& Johnston (1959) \\
\hline Granular appearance & & Mortimer \& Johnston (1959) \\
\hline Surface wrinkles & & Mortimer \& Johnston (1959), Muller (1971) \\
\hline Bud-scar number & Increase & Barton (1950), Bartholomew \& Mittwer (1953) \\
\hline Loss of turgor & & Muller (1971) \\
\hline Cell-wall chitin & Increase & Egilmez et al. (1990) \\
\hline Vacuole size & Increase & Egilmez et al. (1990) \\
\hline Cell fragility & None & Egilmez et al. (1990) \\
\hline Cell lysis & & Mortimer \& Johnston (1959) \\
\hline Mutability of mtDNA & Decrease & James et al. (1975) \\
\hline Telomere length & None & D’mello \& Jazwinski (1991) \\
\hline ERCs & Increase & Sinclair \& Guarente (1997) \\
\hline Specific gene expression & Altered & Egilmez et al. (1989) \\
\hline rRNA levels & Increase & Motizuki \& Tsurugi (1992) \\
\hline Cellular rRNA concn & Decrease & Motizuki \& Tsurugi (1992) \\
\hline Protein synthesis & Decrease & Motizuki \& Tsurugi (1992) \\
\hline Ribosome activity & Decrease & Motizuki \& Tsurugi (1992) \\
\hline Senescence factor & & Egilmez \& Jazwinski (1989) \\
\hline Response to pheromones (haploids) & Decrease & Smeal et al. (1996) \\
\hline Mating ability (haploids) & Decrease & Muller (1985) \\
\hline Sporulation ability (diploids) & Increase & Sando et al. (1973) \\
\hline Cessation of division at $\mathrm{G}_{1} / \mathrm{S}$ & & Egilmez \& Jazwinski (1989), Werner-Washbourne et al. (1993) \\
\hline Generation time & Increase & Mortimer \& Johnston (1959) \\
\hline
\end{tabular}


they increase in size and the implication that once a critical cell size had been exceeded senescence is initiated, was investigated. It has been demonstrated that variations in cell volume caused by different ploidy (Muller, 1971) or by enlarging cells with mating pheromone (Kennedy et al., 1994) did not affect lifespan. In addition, the use of cyclins to control the cell size and achieve a critical volume for division does not influence ageing (M. G. Barker \& K. A. Smart, unpublished data). Mortimer \& Johnston (1959) also suggested that the occurrence of ever increasing numbers of bud scars may limit the availability of surface area for budding and for nutrient exchange with the environment. Studies investigating this hypothesis have obtained inconsistent data (Kennedy et al., 1994) and in addition, increasing the deposition of chitin, the major component of bud scars, using a conditional $c d c 24$ mutant has little effect on longevity (Egilmez \& Jazwinski, 1989). Thus cell size and bud-scar number per se are not the causative initiators of senescence but artefacts of the ageing process.

Another hypothesis for cellular ageing is that division capacity is limited by the length of telomeres. The telomere hypothesis suggests that the number of cell divisions is registered by the gradual loss of telomeric sequences (Holliday, 1996; Chiu \& Harley, 1997). Telomeres stabilize the chromosome and ensure that complete replication occurs (Zakian, 1989), although it is known that they also aid in the attachment of chromosomes to the nuclear matrix (Haber \& Thornburn, 1984; Hastie \& Allshire, 1989; Zakian, 1989).

At the start of replication, DNA polymerase acts in the $5^{\prime}-3^{\prime}$ direction, adding bases with the aid of a primer. The section of the telomere covered by the DNA polymerase is not reproduced, thus causing a shortening of DNA (Olovnikov, 1973), by around 50 base pairs per division (depending on the organism) at the $5^{\prime}$ end (Campisi et al., 1996). This phenomenon has been identified in many organisms (Harley et al., 1990; Hastie et al., 1990; Lindsey et al., 1991) and may act as a biological clock determining the number of divisions prior to senescence in mammalian systems.

In yeast, however, strains displaying telomeres of various lengths have exhibited similar longevities (D'mello \& Jazwinski, 1991; Austriaco \& Guarente, 1997) and it has been suggested that telomere shortening may not even occur in yeast cells (D'mello \& Jazwinski, 1991; Smeal et al., 1996).

However, cytoplasmic senescent factors, specific senescence and youth genes, DNA damage and repair, oxidative damage, and mitochondrial integrity have all been implicated in the mechanism of progression through ageing and senescence.

\section{Cytoplasmic senescence factors}

A potential causative factor involved in the ageing process is the presence of a diffusable cytoplasmic or senescence factor that accumulates in mothers and is transferable to daughters (Egilmez \& Jazwinski, 1989). Within the daughter cell, this agent is diluted, degraded or inactivated to allow the cell to exhibit a full lifespan. In the mother cell, however, the agent is retained and accumulates with each division until a critical concentration is reached, which prevents further rounds of division and triggers senescence (Egilmez \& Jazwinski, 1989; Kennedy et al., 1994). Although the identity and function of this cytoplasmic factor remains unknown (Egilmez \& Jazwinski, 1989), it has been suggested that the senescence factor could be under complex genetic control (Sinclair et al., 1998).

One candidate for this cytoplasmic senescence factor is extrachromosomal rDNA circles (ERCs). Yeast rDNA located on chromosome XII gives rise to circular forms of single rDNA repeats known as 'pop outs' or ERCs (Sinclair et al., 1998). Recently it has been observed that ERCs accumulate in ageing mother cells (Sinclair \& Guarente, 1997) and prematurely induce the senescent phenotype if inserted into young cells (Sinclair \& Guarente, 1997; Sinclair et al., 1997).

\section{Genetics of ageing}

The evidence for genetic control of ageing has gained increasing support over the last ten years. The fact that lifespan is species- or strain specific (Austriaco, 1996; Osiewacz, 1997, Sinclair et al., 1998), accompanied with evidence that senescence may be postponed via breeding (Rose, 1984), comprehensively suggests that ageing is influenced by the genotype of the strain.

It has been postulated that ageing occurs either by a genetic inhibition of metabolically essential proteins and enzymes, such as DNA repair enzymes or antioxidants (Johnson, 1997) or alternatively by gene activation causing the production of proteins that directly inhibit DNA synthesis (Goletz et al., 1994).

Genetic control over lifespan can be investigated by identifying changes within the cell during the lifespan that are not the product of senescence, but rather the cause of it (Kenyon, 1996). A number of genes that influence longevity in yeast have already been identified (Table 2).

LAG1 (Longevity-Assurance Gene 1) and LAG2 are preferentially expressed in young cells, indicating that their protein products exert an effect at this stage of the lifespan, though their exact function remains unknown. Disruption of the LAG2 gene causes a drastic reduction in lifespan (Jazwinski 1993a; Childress et al., 1996), while overexpression causes a significant increase (Jazwinski, 1995).

The RAS genes, which are part of the signal-transduction pathways involved in sensing the nutritional status of the cell and in responding to stresses, have also been reported to affect longevity. Overexpression of RAS1 has been found to have no effect on lifespan, while deletion of RAS1 and overexpression of RAS2 have been found to increase lifespan by around 30\% (Sun et al., 
Table 2. Genes associated with longevity in Saccharomyces cerevisiae

\begin{tabular}{|lll|}
\hline Gene & \multicolumn{1}{c|}{ Function } & \multicolumn{1}{c|}{ Reference } \\
\hline LAG1 & Unknown & D'mello et al. (1994) \\
LAG2 & Unknown & Jazwinski (1995) \\
RAS1 & Nutritional status & Sun et al. (1994) \\
RAS2 & Nutritional status & Sun et al. (1994) \\
SIR4 & Gene silencing & Kennedy et al. (1995) \\
AGE & Stress response & Kennedy et al. (1995) \\
SIR2/3/4 & rDNA repair & Kennedy et al. (1995) \\
SGS1 & DNA helicase & Sinclair \& Guarente (1997) \\
RAD9 & Cell cycle & Kennedy et al. (1994) \\
\hline
\end{tabular}

1994). These long-lived yeasts show an increased efficiency in terms of metabolic capacity and productivity (Jazwinski, 1996).

Genetic analysis of individuals exhibiting increased lifespan during starvation stress led to the identification of four 'youth' genes (Kennedy et al., 1995; Kennedy \& Guarente, 1996). One of these, SIR4, had several functions including chromatic silencing (Osiewacz, 1997) and repression of genes placed near telomeres (telomere position effect) (Aparicio et al., 1991; Shore, 1995). Kennedy et al. (1995) demonstrated that SIR4 was important in lifespan regulation and may trigger senescence by silencing a stress-response gene known as $A G E$. The SIR4 gene belongs to a family of SIR genes. SIR proteins are involved in DNA repair and nucleolus protection. Towards the end of the lifespan the nucleolus becomes enlarged and fragments (Sinclair et al., 1998); thus it appears that silencing, DNA repair and genome stability are important in determining lifespan (Sinclair et al., 1998).

Other genes involved in DNA repair and integrity have been implicated in the mechanism of yeast ageing and senescence. DNA helicases have been demonstrated to contribute to premature ageing syndromes in humans. The SGS1 (Slow-Growth Suppresser) gene, which encodes a yeast DNA helicase is also a longevityassurance gene (Sinclair \& Guarente, 1997) and its deletion reduces the lifespan of $S$. cerevisiae. RAD9, a gene involved in cell-cycle checkpoint regulation is also thought to be a youth gene, as deletion shortens lifespan (Kennedy et al., 1994).

\section{Oxidative stress and the free-radical theory of ageing}

Free radicals and reactive oxygen species (ROS) were first identified in yeast in 1954 (Commenor et al., 1954) and are increasingly described as important factors involved in the phenomenon of biological ageing (Nohl, 1993).

Organisms undergoing aerobic respiration are frequently subjected to slow but continuous damage to their cellular components caused by free-radical stress (Harman, 1956, 1981, 1992). Free radicals can occur naturally due to radiation or from the use of oxygen by aerobic cells. Oxygen is a highly reactive molecule that can form ROS, including the superoxide anion $\left(\mathrm{O}_{2}{ }^{-}\right)$, hydrogen peroxide $\left(\mathrm{H}_{2} \mathrm{O}_{2}\right)$ and the hydroxyl group $(\mathrm{OH})$ (Jamieson, 1995). These free radicals cause damage to almost all cellular constituents. The most susceptible are proteins and lipid membranes (Wolff et al., 1986), although more substantial damage can be caused due to the mutagenesis of DNA (Storz et al., 1987).

Cells exhibit defined anti-oxidant defences that are depleted throughout the life cycle and are comprised of enzymic and non-enzymic antioxidants (Jamieson, 1998). These defence mechanisms act to scavenge free radicals or repair enzymes by removing and replacing damaged molecules. Under normal conditions, antioxidant defence mechanisms are capable of maintaining ROS at harmless levels, but prolonged exposure to free radicals can eventually result in an inability to prevent cellular damage (Jamieson, 1995). The extent of oxidative damage incurred and the subsequent susceptibility to further damage increases with age (Kale \& Jazwinski, 1996). It is likely that the cause of these phenomena are due to an increase in oxidant production, a decline in antioxidant defence mechanisms or a decline in the efficiency of repair mechanisms (Sohal \& Weindruch, 1996). Recent advances in this field have shown that deletion of genes responsible for antioxidant defence mechanisms cause a reduction in lifespan (Barker et al., 1999; Wawryn et al., 1999).

\section{Mitochondrial DNA damage and ageing}

Mitochondria are the major intracellular source and target of ROS, due to the close proximity of free radicals produced by metabolism (Wei et al., 1998). Mitochondrial DNA is subjected to attack in a similar fashion to nuclear DNA; however mitochondrial DNA is less stable than nuclear DNA due to the absence of stabilizing histone proteins (Yakes \& Van Houten, 1997). Mitochondrial DNA is known to incur irreparable damage over time (Wallace, 1992), leading to 
mitochondrial disfunction (Osiewacz, 1997) and ageing (Miguel \& Fleming, 1986; Wei, 1998).

The role of mitochondria in ageing is becoming increasingly apparent. It has been demonstrated that the mitochondrial transmembrane proteins encoded by BAP37 and PHB1 (Coates et al., 1997) are required to ensure longevity, and mitochondrial DNA is known to be necessary for resistance to oxidative stress in yeast (Grant et al., 1997).

Lifespan analysis of respiratory-deficient yeast suggests that the impact of petite mutations on longevity may be strain specific (Kirchman et al., 1999). As the mitochondria are the source of ROS, it has been suggested that mitochondrial dysfunction could lead to reduced levels of stress (Longo et al., 1996; Guidot et al., 1993) and therefore an enhanced longevity. Alternatively, the energetic requirement of free-radical scavengers implies that lifespan would be extended by the presence of fully functional mitochondria (Grant et al., 1997). Berger \& Yaffe (1998) observed a 40\% reduction in lifespan for petite mutants, supporting the latter hypothesis. Kirchman et al. (1999) also reported a reduced lifespan for several petite mutants; however analysis of a longlived subpopulation of a yeast strain, YPK9, identified these individuals as being respiratory deficient.

\section{Measuring yeast cell age}

The number of divisions an individual cell has undertaken, or budding index, is the most widely accepted indicator of cell age, and can be directly calculated by analysis of the cell wall for bud scars using confocal microscopy (Smart, 1999). The budding index may also be indirectly determined by monitoring a cell throughout its lifespan to determine its division capacity. To achieve this, a cohort of no less than 60 cells must be individually monitored to establish the number of divisions undertaken. This process requires the use of a microscope with tetrad stage and micromanipulator. Individual cells are monitored throughout their replicative lifespans, from newly emerged bud to senescent mother cell. By recording the number of divisions accomplished by each cell, specific mortality profiles for each strain are obtained (Fig. 4). Using this method, cellular senescence

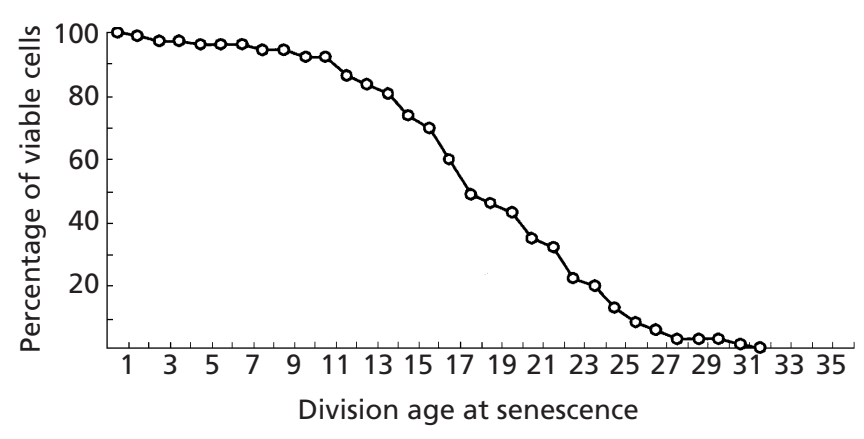

Fig. 4. Mortality profile of the haploid strain SEY6210. has been demonstrated in haploid (Austriaco, 1996; Egilmez et al., 1990; Muller et al., 1980), diploid (Mortimer \& Johnston, 1959; Muller et al., 1980) and polyploid (Muller et al., 1980; Barker \& Smart, 1996) yeast strains.

\section{Ageing in brewing yeast}

It has been demonstrated that polyploid laboratory strains (Muller et al., 1980), and brewing lager (Barker \& Smart, 1996) and ale (C. D. Powell, unpublished observation) strains exhibit replicative senescence. For brewing yeast, the mean lifespan is strain specific within the range 10-30 divisions (C. D. Powell, unpublished data). Once the mean divisional capacity of a given yeast strain has been determined, certain assumptions can be made with regard to its suitability for industrial use. For example, it would be anticipated that yeast with a low Hayflick limit would not be appropriate for continuous fermentations or immobilized systems. In each system, cell division does occur but the daughter cells, as opposed to the mother cells, tend to be eluted from the reactor (Hough, 1961; Lyons \& Hough, 1970; K. A. Smart, unpublished observations). Thus inadvertently a proportion of young cells is continuously removed from the population and the resident population becomes progressively older with time (Smart, 1999).

For brewing yeast, very little has been reported regarding the physiological modifications that occur as a function of individual cell ageing. Our laboratory reported an extensive increase in cell size throughout the lifespan (Barker \& Smart, 1996; Fig. 5). Interestingly, the increase in size of the mother cell did not result in a corresponding increase in size for each successive bud produced (Barker \& Smart, 1996), except in very rare instances when the newly formed bud could equal the size of its ageing mother. At the end of brewery fermentations, the vessel contents are cooled to $2-4{ }^{\circ} \mathrm{C}$, which facilitates the sedimentation of yeast into the

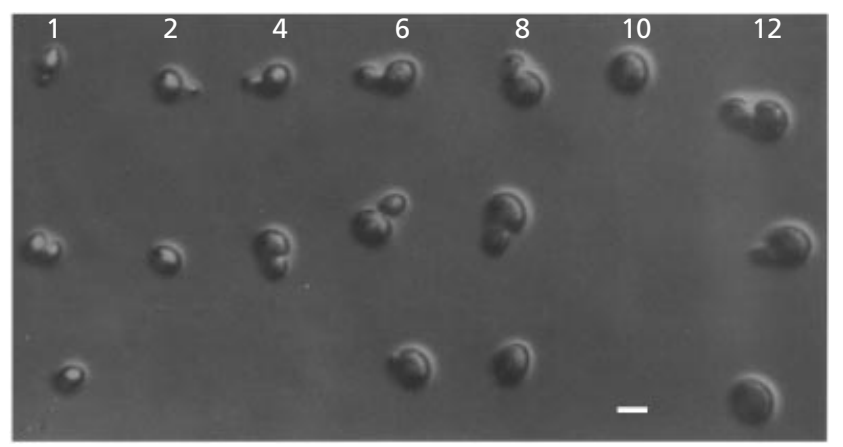

Fig. 5. A lager yeast strain (L1116) cell array constructed by micromanipulation showing the increase in cell size with successive cell divisions. All cells were derived from the same mother and are arranged in order of age. Numbers represent the total number of divisions accomplished by each cell. Bar, $8 \mu \mathrm{m}$. Reproduced with permission from Barker \& Smart (1996) and the American Society of Brewing Chemists. 


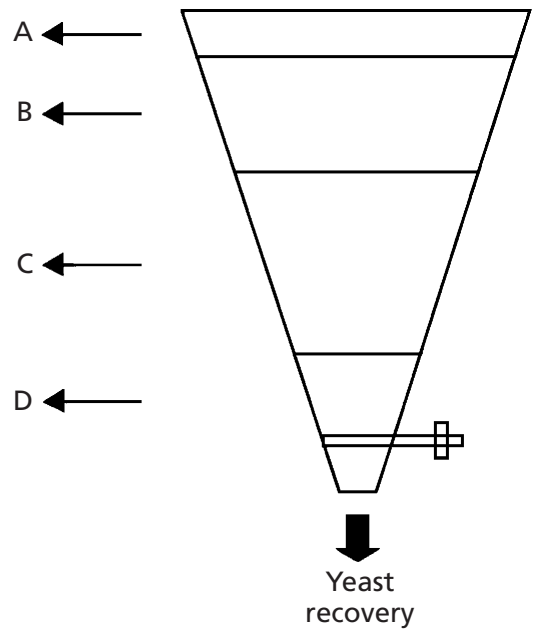

Fig. 6. Schematic illustrating the stratification of yeast during sedimentation. A indicates the youngest cell fraction, $D$ the predominantly aged fraction. A, B and C represent the fractions reused for successive fermentations with traditional cropping techniques. Fractions $B$ and $C$ represent yeast removed from the vessel during warm cropping.

fermenter cone. This settling process is known to be rate zonal in nature, with larger cells settling faster than their smaller companions. Deans et al. (1997) demonstrated that older cells were indeed more abundant in lower than in higher regions of the cone (Fig. 6), supporting the hypothesis put forward by Barker \& Smart (1996) that age stratification could occur as a result of the preferential sedimentation of the older cell population. The presence of an age gradient within the cone becomes of significance when considering the mechanism by which yeast is removed from the vessel prior to storage and subsequent serial repitching. Typically, the cropped yeast is 'run down' from the fermenter in two fractions, termed cuts. The first cut, consisting of larger, older and dead cells together with protein debris ('trub') is discarded as waste. The second cut, consisting of middleaged and virgin cells, is transferred to a yeast collection vessel prior to repitching into a fresh fermentation. An alternative mechanism is to remove yeast from the cone prior to vessel cooling so that some yeast remains in suspension (Loveridge et al., 1999). This procedure, known as 'warm' or 'early' cropping, would be anticipated to result in a greater proportion of aged individuals to be selected for serial repitching (Loveridge et al., 1999). Successively cropping and repitching a specific layer of yeast in this way could inadvertently select for cells of a particular size and therefore age. During laboratory batch culturing, a normal cell population consists of approximately $50 \%$ virgin cells, $25 \%$ first generation cells, $12.5 \%$ second generation cells and so on; therefore it is possible that cropping could have implications for subsequent fermentations due to selective pressures and the disruption of population dynamics (Barker \& Smart, 1996). It is likely that as genes are differentially expressed throughout the lifespan, a good

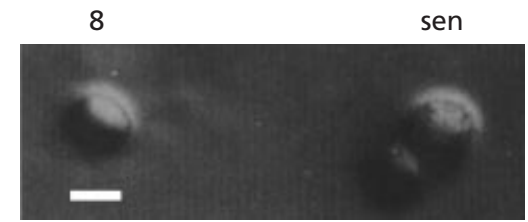

Fig. 7. A photograph taken using a light microscope of the strain L1116 illustrating a viable, eight-division-old cell (8) and a senescing granulated and wrinkled cell (sen) approaching the end of its lifespan. Bar, $8 \mu \mathrm{m}$. Reproduced with permission from Barker \& Smart (1996) and the American Society of Brewing Chemists.

'age balance' would result in optimum fermentation performance. Seeding fermentations with a population skewed towards an imbalance of either young or aged cells could result in an inappropriate expression of genes. This could influence a number of metabolic parameters, ultimately affecting the fermentation profile, leading to an inconsistent process and a product of poorer quality.

Selection for a population enriched with older cells could impact on fermentation performance in several ways. Increased mortality accompanied by a slower division rate would reduce the effective size of the inoculum and slow the growth of the culture. In addition, for some brewing yeast strains, older mother cells exhibit an increased propensity to retain daughter cells throughout their lifespan (Barker \& Smart, 1996). The impact of daughter-cell retention on fermentation performance is unclear, but it is postulated that such cells may form the nuclei for floc formation much in the same way as chain-forming brewing yeast strains behave (Barker \& Smart, 1996). In addition, the aged phenotype of senescent polyploid strains is characterized by the occurrence of a granular appearance (Fig. 7), accompanied by wrinkling at the cell surface (Barker \& Smart, 1996). By generating age-synchronous populations using rate zonal sedimentation techniques, this may be demonstrated using scanning electron microscopy (Fig. 8). It is well known that a rough cell surface topography favours cell-to-cell adhesion during the onset of flocculation (Day et al., 1975; Smart et al., 1995; Rhymes \& Smart, 1996), and it would be expected that discrete older wrinkled cells would be more flocculent than discrete younger smoother cells. It has been suggested that the development of surface wrinkles and the retention of daughter cells by a significant number of elder mothers may inadvertently lead to premature flocculation and subsequently to incomplete ('stuck') fermentations.

Throughout most of the lifespan, the time taken to progress through the cell cycle is uniform. However, during the last $20 \%$ of the lifespan, the division time dramatically increases (Mortimer \& Johnston, 1959), probably due to inefficient and slow progression through $\mathrm{G}_{1}$ to START. Thus seeding a fermentation with yeast 


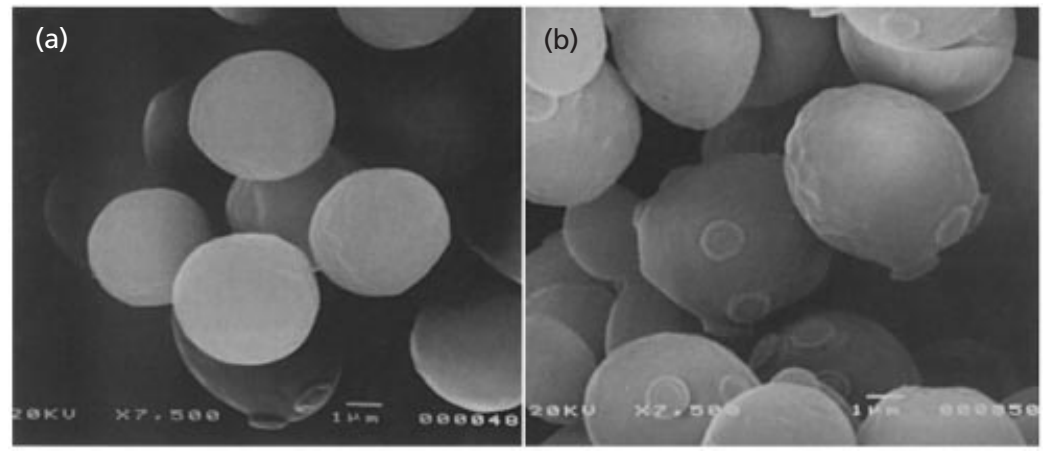

Fig. 8. Scanning electron micrographs of lager brewing yeast strain (L1116) cells taken from a set of sucrose gradients used to fractionate a six-division-old cell preparation. (a) Cells from the uppermost virgin band. (b) Cells from the six-divisionold mother band, illustrating the onset of wrinkling at the cell surface. Reproduced with permission from Barker \& Smart (1996) and the American Society of Brewing Chemists.

consisting primarily of aged cells would result in an extended lag phase in the fermenter due to slow progression through the cell cycle. If the pitching yeast consisted primarily of newly budded virgin cells, the time taken to reach the critical size required for the first division would result in a slight delay in the onset of growth. However middle-aged mothers would rapidly divide, reducing fermentation lag time. Therefore, it has been suggested by Smart (1999) that mother cells that are young to middle aged represent the most active portion of the pitch population in terms of rapid growth and yeast biomass production.

In conclusion, individual cell ageing in brewing strains may influence fermentation performance where yeast handling in the brewery allows for the inadvertent selection of yeast populations enriched for very young or aged cells.

\section{Acknowledgements}

Christopher Powell is supported by a BBSRC Industrial CASE studentship with Bass Brewers. Sylvie Van Zandycke is supported by an Oxford Brookes University Studentship. The authors are grateful to the Directors of Bass Brewers for permission to publish this review.

\section{References}

Aparicio, O. M., Billington, B. L. \& Gottschling, D. E. (1991). Modifiers of position effect are shared between telomeric and silent mating-type loci in Saccharomyces cerevisiae. Cell 66, 1279-1287.

Austriaco, N. R. (1996). To bud until death: the genetics of ageing in the yeast, Saccharomyces. Yeast 12, 623-630.

Austriaco, N. \& Guarente, L. (1997). Changes of telomere length cause reciprocal changes in the lifespan of mother cells in Saccharomyces cerevisiae. Proc Natl Acad Sci USA 94, 9768-9772.

Barker, M. G. \& Smart, K. A. (1996). Morphological changes associated with the cellular ageing of a brewing yeast strain. J Am Soc Brew Chem 54, 121-126.

Barker, M. G., Brimage, L. J. E. \& Smart, K. A. (1999). Effect of $\mathrm{Cu}, \mathrm{Zn}$ superoxide dismutase disruption mutation on replicative senescence in Saccharomyces cerevisiae. FEMS Microbiol Lett 177, 199-204.

Bartholomew, J. W. \& Mittwer, T. (1953). Demonstration of yeast bud scars with the electron microscope. J Bacteriol 65, 272-275.
Barton, A. A. (1950). Some aspects of cell division in Saccharomyces cerevisiae. J Gen Microbiol 4, 84-86.

Bell, S. P. \& Stillman, B. (1992). ATP-dependent recognition of eukaryotic origins of DNA replication by a multiprotein complex. Nature 357, 128-134.

Berger, K. B. \& Yaffe, M. P. (1998). Prohibitin family members interact genetically with mitochondrial inheritance components in Saccharomyces cerevisiae. Mol Cell Biol 18, 4043-4052.

Breeden, L. (1996). Start-specific transcription in yeast. Curr Top Microbiol Immunol 208, 95-127.

Campisi, J. (1996). Replicative senescence: an old lives' tale? Cell 84, 497-500.

Campisi, J., Dimri, G. \& Hara, E. (1996). Control of replicative senescence. In Handbook of the Biology of Ageing, 4th edn, pp. 121-149. Edited by E. Schneider \& J. Rowe. New York: Academic Press.

Childress, A. M., Franklin, D. S., Pinswasdi, C., Kale, S. \& Jazwinski, S. M. (1996). LAG2, a gene that determines yeast longevity. Microbiology 142, 2289-2297.

Chiu, C. P. \& Harley, C. B. (1997). Replicative senescence and cell immortality: the role of telomeres and telomerase. Proc Soc Exp Biol Med 214, 99-106.

Coates, P. J., Jamieson, D. J., Smart, K. A. \& Hall, P. A. (1997). The prohibitin family of mitochondrial proteins regulate replicative lifespan. Curr Biol 7, R607-R610.

Commenor, B., Townsend, J. \& Pake, G. E. (1954). Free radicals in biological materials. Nature 174, 689-691.

D'Amore, T. (1992). Improving yeast fermentation performance. J Inst Brew 98, 375-382.

Day, A. W., Poon, N. H. \& Stewart, G. G. (1975). Fungal fimbriae. III. The effect on flocculation in Saccharomyces cerevisiae. Can J Microbiol 12, 558-564.

Deans, K., Pinder, A., Catley, B. J. \& Hodgson, J. A. (1997). Effects of cone cropping and serial repitch on the distribution of cell ages in brewery yeast. Proc Eur Brew Con 26, 469-476.

Diffley, J. F. (1995). The initiation of DNA replication in the budding yeast cell division cycle. Yeast 11, 1651-1670.

Diffley, J. F. \& Cocker, J. H. (1992). Protein-DNA interactions at a yeast replication origin. Nature 357, 169-172.

D'mello, N. P. \& Jazwinski, S. M. (1991). Telomere length constancy during aging of Saccharomyces cerevisiae. J Bacteriol 173, 6709-6713.

D'mello, N. P., Childress, A. M., Kale, S.P., Pinswadi, C. \& Jazwinski, S. M. (1994). Cloning and characterisation of LAG1, a longevity assurance gene in yeast. J Biol Chem 269, 15451-15459. Egilmez, N. K. \& Jazwinski, S. M. (1989). Evidence for the 
involvement of a cytoplasmic factor in the aging of the yeast Saccharomyces cerevisiae. J Bacteriol 171, 37-42.

Egilmez, N. K., Chen, J. B. \& Jazwinski, S. M. (1989). Specific alterations in transcript prevalence during the yeast life-span. $J$ Biol Chem 264, 14312-14317.

Egilmez, N. K., Chen, J. B. \& Jazwinski, S. M. (1990). Preparation and partial characterisation of old yeast cells. J Gerontol 45, B9-B17.

Fleming, J. E., Walton, J. K., Dubitsky, R. \& Bensch, J. G. (1988). Aging results in an unusual expression of Drosophila heat-shock proteins. Proc Natl Acad Sci USA 85, 4099-4103.

Forsburg, S. L. (1994). Cell cycle - in and out of the cell cycle. Curr Biol 4, 828-830.

Forsburg, S. L. \& Nurse, P. (1991). Cell-cycle regulation in the yeasts Saccharomyces cerevisiae and Schizosaccharomyces pombe. Annu Rev Cell Biol 7, 227-256.

Futcher, B. (1993). Analysis of the cell cycle in Saccharomyces cerevisiae. In The Cell Cycle: a Practical Approach, pp. 69-92. Edited by P. Fantes \& R. Brooks. Oxford: IRL Press.

Futcher, B. (1996). Cyclins and the wiring of the yeast cell cycle. Yeast 12, 1635-1646.

George, E. (1996). The influence of brewing yeast physiology on cell surface physical properties. PhD thesis, Oxford Brookes University.

Goletz, T. J., Smith, J. R. \& Pereira-Smith, O. M. (1994). Molecular genetic approaches to the study of cellular senescence. Cold Spring Harbor Symp Quant Biol 59, 59-66.

Grant, C. M., Maclver, F. H. \& Dawes, I. W. (1997). Mitochondrial function is required for resistance to oxidative stress in the yeast Saccharomyces cerevisiae. FEBS Lett 410, 219-222.

Guidot, D. M., McCord, J. M., Wright, R. M. \& Repine, J. E. (1993). Absence of electron transport $\left(\mathrm{Rho}^{0}\right.$ state) restores growth of a manganese-superoxide dismutase-deficient Saccharomyces cerevisiae in hyperoxia. J Biol Chem 268, 26699-26703.

Haber, J. E. \& Thornburn, P. C. (1984). Healing of broken linear dicentric chromosomes in yeast. Genetics 106, 207-226.

Hammond, J. R. M. (1993). Brewers yeast. In The Yeasts, vol. 5, 2nd edn, pp. 7-67. Edited by A. H. Rose \& J. S. Harrison. London: Academic Press.

Harley, C. B., Futcher, A. B. \& Greider, C. W. (1990). Telomeres shorten during aging of human fibroblasts. Nature 345, 458-460.

Harman, D. (1956). Ageing: a theory based on free radical and radiation chemistry. J Gerontol 114, 298-300.

Harman, D. (1981). The aging process. Proc Natl Acad Sci USA 78, 7124-7128.

Harman, D. (1992). Free radical theory of aging. Mutat Res 275, 257-266.

Hartwell, L. H. (1974). Saccharomyces cerevisiae cell cycle. Bacteriol Rev 38, 164-198.

Hartwell, L. H. (1978). Cell division from a genetic perspective. $J$ Cell Biol 77, 626-637.

Hartwell, L. H. \& Weinhart, T. A. (1989). Checkpoints - controls that ensure the order of cell-cycle events. Science 246, 629-634.

Hartwell, L. H., Culotti, J., Pringle, J. R. \& Reid, B. (1974). Genetic control of the cell division cycle in yeast. Science 183, 46-51.

Hastie, N. D. \& Allshire, R. C. (1989). Human telomeres: fusion and interstitial sites. Trends Genet 5, 326-331.

Hastie, N. D., Dempster, M., Dunlop, M. G., Thompson, A. M., Green, D. K. \& Allshire, R. C. (1990). Telomere reduction in human colorectal carcinoma and with aging. Nature 346, 866-868.

Hayflick, L. (1965). The limited in vitro lifespan of human diploid cell strains. Exp Cell Res 37, 614-636.

Hayflick, L. \& Moorhead, P. S. (1961). The serial cultivation of human diploid cell strains. Exp Cell Res 25, 585-621.

Holliday, R. (1996). Endless quest. Bioessays 18, 3-5.

Hough, J. S. (1961). Estimation of the age of cells in a population of yeast. J Inst Brew 67, 494-495.

James, A. P., Johnson, B. F., Inhaber, E. R. \& Gridgeman, N. T. (1975). A kinetic analysis of spontaneous $\psi$ mutations in yeast. Mutat Res 30, 199-208.

Jamieson, D. J. (1995). The effect of oxidative stress on Saccharomyces cerevisiae. Redox Rep 1, 89-95.

Jamieson, D. J. (1998). Oxidative stress responses of the yeast Saccharomyces cerevisiae. Yeast 14, 1511-1527.

Jazwinski, S. M. (1990a). Aging and senescence of the budding yeast Saccharomyces cerevisiae. Mol Microbiol 4, 337-343.

Jazwinski, S. M. (1990b). An experimental system for the molecular analysis of the aging process: the budding yeast Saccharomyces cerevisiae. J Gerontol 45, B68-B74.

Jazwinski, S. M. (1993a). Genes of youth: genetics of aging in baker's yeast. ASM News 59, 172-178.

Jazwinski, S. M. (1993b). The genetics of aging in the yeast Saccharomyces cerevisiae. Genetica 91, 35-51.

Jazwinski, S. M. (1995). Nuclear genes in ageing. In Molecular Aspects of Aging, pp. 15-28. Edited by K. Esser \& G. M. Martin. Chichester: Wiley.

Jazwinski, S. M. (1996). Longevity, genes, and aging. Science 273, 54-58.

Johnson, T. E. (1997). Genetic influences on aging. Exp Gerontol $32,11-22$.

Johnson, B. F. \& Lu, C. (1975). Morphometric analysis of yeast cells. IV. Increase of the cylindrical diameter of Schizosaccharomyces pombe during the cell cycle. Exp Cell Res 95, 154-158.

Kale, S. P. \& Jazwinski, S. M. (1996). Differential response to UV stress and DNA damage during the yeast replicative life span. Dev Genet 18, 154-160.

Katz, M. L., Robison, W. G., Jr, Herrmann, R. K., Groome, A. B. \& Bieri, J. G. (1984). Lipofuscin accumulation resulting from senescence and vitamin E deficiency: spectral properties and tissue distribution. Mech Ageing Dev 25, 149-159.

Kennedy, B. K. \& Guarente, L. (1996). Genetic analysis of aging in Saccharomyces cerevisiae. Trends Genet 12, 355-358.

Kennedy, B. K., Austriaco, N. R. \& Guarente, L. (1994). Daughter cells of Saccharomyces cerevisiae from old mothers display a reduced life span. J Cell Biol 127, 1985-1993.

Kennedy, B. K., Austriaco, N. R., Zhang, J. \& Guarente, L. (1995). Mutation in the silencing gene SIR4 can delay aging in $S$. cerevisiae. Cell 80, 485-496.

Kenyon, C. (1996). Ponce d'elegans : genetic quest for the fountain of youth. Cell 84, 501-504.

Kirchman, P. A., Kim, S., Lai, C.-Y. \& Jazwinski, S. M. (1999). Interorganelle signalling is a determinant of longevity in Saccharomyces cerevisiae. Genetics 152, 179-190.

Kuntzel, H., Schultz, A. \& Ehbrecht, I.-M. (1996). Cell cycle control and initiation of DNA replication in Saccharomyces cerevisiae. Biol Chem 377, 481-487. 
Lew, D. J. \& Reed, S. I. (1995). A cell cycle checkpoint monitors cell morphogenesis in budding yeast. Curr Opin Genet Dev 129, 739-740.

Lindsey, J., McGill, N. I., Lindsey, L. A., Green, D. K. \& Cooke, H. J. (1991). In vivo loss of telomeric repeats with age in humans. Mutat Res 256, 45-48.

Longo, V. D., Gralla, E. B. \& Valentine, J. S. (1996). Superoxide dismutase activity is essential for stationary phase survival in Saccharomyces cerevisiae. J Biol Chem 271, 12275-12280.

Loveridge, D., Ruddlesden, J. D., Noble, C. S. \& Quain, D. E. (1999). Improvements in brewery fermentation performance by 'early' yeast cropping and reduced yeast storage time. In Proceedings of the 7th Scientific and Technical Convention, pp. 95-99. Nairobi: Institute of Brewing Africa Section.

Lydall, D. \& Weinert, T. (1996). From DNA damage to cell cycle arrest and suicide: a budding yeast perspective. Curr Opin Genet Dev 6, 4-11.

Lyons, T. P. \& Hough, J. S. (1970). The role of yeast cell walls in brewing. Brew Dig Aug, 52-60.

McCaig, R. \& Bendiak, D. S. (1985). Yeast handling studies. I. Agitation of stored pitching yeast. J Am Soc Brew Chem 43, 114-118.

Miguel, J. \& Fleming, J. (1986). Theoretical and experimental support for an oxygen radical-mitochondrial injury hypothesis of cell aging. In Free Radicals, Aging and Degenerative Diseases, pp. 51-74. Edited by J. E. Johnson, D. Harman, R. Walford \& J. Miguel. New York: Liss.

Mitchison, J. M. (1971). The Biology of the Cell Cycle. London: Cambridge University Press.

Monch, D., Krugwer, E. \& Stahl, U. (1995). Effects of stress on brewery yeasts. Monatsschr Brau 48, 288-299.

Mortimer, R. K. \& Johnston, J. R. (1959). Life span of individual yeast cells. Nature 183, 1751-1752.

Motizuki, M. \& Tsurugi, K. (1992). The effect of aging on protein synthesis in the yeast Saccharomyces cerevisiae. Mech Ageing Dev 64, 235-245.

Muller, I. (1971). Experiments on ageing in single cells of Saccharomyces cerevisiae. Arch Mikrobiol 77, 20-25.

Muller, I. (1985). Parental age and the life-span of zygotes of Saccharomyces cerevisiae. Antonie Leeuwenhoek 51, 1-10.

Muller, I., Zimmermann, M., Becker, D. \& Flomer, M. (1980). Calender lifespan versus budding lifespan of Saccharomyces cerevisiae. Mech Aging Dev 12, 47-52.

Murray, A. (1994). Cell cycle checkpoints. Curr Opin Cell Biol 6, 872-876.

Nohl, H. (1993). Involvement of free radicals in ageing: a consequence or cause of senescence. Br Med Bull 49, 653-667.

Nurse, P. (1997). Regulation of the eukaryotic cell cycle. Eur J Cancer 33, 1002-1004.

Nurse, P., Masui, Y. \& Hartwell, L. (1998). Understanding the cell cycle. Nat Med 4, 1103-1106.

O'Connell, M. J. \& Nurse, P. (1994). How cells know they are in $\mathrm{G}^{1}$ or $\mathrm{G}^{0}$. Curr Opin Cell Biol 6, 867-871.

Oliver, S. G. (1996). From DNA sequence to biological function. Nature 379, 597-600.

Olovnikov, A. M. (1973). A theory of marginotomy: the incomplete copying of template margin in enzymatic synthesis of polynucleotides and biological significance of the phenomenon. $J$ Theor Biol 41, 181-190.
Osiewacz, H. D. (1997). Genetic regulation of aging. J Mol Med 75, 715-727.

Pringle, J. R. \& Hartwell, L. H. (1981). The Saccharomyces cell cycle. In The Molecular Biology of the Yeast Saccharomyces, pp. 97-142. Edited by J. Strathern, E. W. Jones \& J. R. Broach. Cold Spring Harbor Laboratory, NY: Cold Spring Harbor Press.

Rhymes, M. R. \& Smart, K. A. (1996). Effect of starvation on the flocculation of ale and lager yeasts. Am Soc Brew Chem 54, 50-56.

Rose, M. R. (1984). Laboratory evolution of postponed senescence in Drosophila melanogaster. Evolution 38, 1004-1010.

Sando, N., Maeda, M., Endo, T., Oka, R. \& Hayashibe, M. (1973). Induction of meiosis and sporulation in differently aged cells of Saccharomyces cerevisiae. J Gen Appl Microbiol 19, 359-373.

Shore, D. (1995). Silence is golden. Curr Biol 5, 822-825.

Sinclair, D. A. \& Guarente, L. (1997). Extrachromosomal rDNA circles - a cause of aging in yeast. Cell 91, 1033-1042.

Sinclair, D. A., Mills, K. \& Guarente, L. (1997). Accelerated aging and nucleolar fragmentation in yeast sgs1 mutants. Science 277, 1313-1316.

Sinclair, D. A., Mills, K. \& Guarente, L. (1998). Molecular mechanisms of yeast aging. Trends Biochem Sci 23, 131-134.

Smart, K. A. (1999). Ageing in brewing yeast. Brew Guardian 128, 19-24.

Smart, K. A., Boulton, C. A., Hinchcliffe, E. \& Molzahn, S. (1995). Effect of physiological stress on the surface properties of brewing yeast. J Am Soc Brew Chem 53, 33-38.

Smeal, T., Claus, J., Kennedy, B., Cole, F. \& Guarente, L. (1996). Loss of transcriptional silencing causes sterility in old mother cells of Saccharomyces cerevisiae. Cell 84, 633-642.

Smith, J. R. \& Pereira-Smith, O. M. (1996). Replicative senescence - implications for in vivo aging and tumour suppression. Science 273, 63-67.

Sohal, R. S. \& Weindruch, R. (1996). Oxidative stress, caloric restriction, and aging. Science 273, 59-63.

Stewart, G. (1996). Yeast performance and management. The Brewer 82, 211.

Storz, G., Christman, M. F., Sies, H. \& Ames, B. N. (1987). Spontaneous mutagenesis and oxidative damage to DNA in Salmonella typhimurium. Proc Natl Acad Sci USA 84, 8917-8921.

Sun, J., Kale, S. P., Childress, A. M., Pinswasdi, C. \& Jazwinski, S. M. (1994). Divergent roles of RAS1 and RAS2 in yeast longevity. J Biol Chem 269, 18638-18645.

Walker, G. M. (1998). Control of yeast growth and cell division. In Yeast Physiology and Biotechnology, pp. 112-127. Edited by G. M. Walker. Chichester: Wiley.

Wallace, D. C. (1992). Mitochondrial genetics - a paradigm for aging and degenerative diseases. Science 256, 628-632.

Wawryn, J., Krzepilko, A., Myszka, A. \& Bilinski, T. (1999). Deficiency in superoxide dismutase shortens life span of yeast cells. Acta Biochim Pol 46, 249-253.

Wei, Y. H. (1998). Oxidative stress and mitochondrial DNA mutations in human aging. Proc Soc Exp Biol Med 217, 53-63.

Wei, W., Nurse, P. \& Broek, D. (1993). Yeast cells can enter a quiescent state through $\mathrm{G}^{1}, \mathrm{~S}, \mathrm{G}^{2}$ or M-phase of the cell-cycle. Cancer Res 53, 1867-1870.

Wei, Y. H., Pang, C. Y., Lee, H. C. \& Lu, C. Y. (1998). Roles of mitochondrial DNA mutation and oxidative damage in human aging. Curr Sci 74, 887-893.

Weinert, T. A., Kiser, G. L. \& Hartwell, L. H. (1994). Mitotic 
checkpoint genes in budding yeast and the dependence of mitosis on DNA replication and repair. Genes Dev 8, 652-665.

Werner-Washbourne, M., Braun, E., Johnston, G. C. \& Singer, R. A. (1993). Stationary phase in the yeast Saccharomyces cerevisiae. Microbiol Rev 57, 383-401.

Wheals, A. E. (1987). Biology of the cell cycle in yeasts. In The Yeasts, vol. 1, Biology of Yeasts, 2nd edn, pp. 283-377. Edited by A. H. Rose \& J. S. Harrison. London: Academic Press.
Wolff, S. P., Garner, A. \& Dean, R. T. (1986). Free-radicals, lipids and protein degradation. Trends Biochem Sci 11, 27-31.

Yakes, F. M. \& Van Houten, B. (1997). Mitochondrial DNA damage is more extensive and persists longer than nuclear DNA damage in human cells following oxidative stress. Proc Natl Acad Sci USA 94, 514-519.

Zakian, V. A. (1989). Structure and function of telomeres. Annu Rev Genet 23, 579-604. 